This item was submitted to Loughborough's Research Repository by the author.

Items in Figshare are protected by copyright, with all rights reserved, unless otherwise indicated.

\title{
Wetting properties of cosmetic polymeric solutions on hair tresses
}

\section{PLEASE CITE THE PUBLISHED VERSION}

http://dx.doi.org/10.1016/j.colcom.2016.02.001

\section{PUBLISHER}

(C) The Authors. Published by Elsevier Ltd

\section{VERSION}

VoR (Version of Record)

\section{PUBLISHER STATEMENT}

This work is made available according to the conditions of the Creative Commons Attribution-NonCommercialNoDerivatives 4.0 International (CC BY-NC-ND 4.0) licence. Full details of this licence are available at: https://creativecommons.org/licenses/by-nc-nd/4.0/

\section{LICENCE}

CC BY-NC-ND 4.0

\section{REPOSITORY RECORD}

Trybala, Anna, A. Bureiko, Nina Kovalchuk, Omid Arjmandi-Tash, Zehan Liu, and Victor Starov. 2017. "Wetting Properties of Cosmetic Polymeric Solutions on Hair Tresses". figshare. https://hdl.handle.net/2134/24224. 
Rapid Communication

\title{
Wetting properties of cosmetic polymeric solutions on hair tresses
}

\author{
A. Trybala ${ }^{\text {a }}$, A. Bureiko ${ }^{\text {b }}$, N. Kovalchuk ${ }^{\text {a,c }}$, O. Arjmandi-Tash ${ }^{\text {a }}$, Z. Liu ${ }^{\text {a }}$, V. Starov ${ }^{\mathrm{a}, *}$ \\ a Department of Chemical Engineering, Loughborough University, UK \\ b Procter \&' Gamble, USA \\ ${ }^{\mathrm{c}}$ Institute of Biocolloid Chemistry, Kiev, Ukraine
}

\section{A R T I C L E I N F O}

\section{Article history:}

Received 18 December 2015

Received in revised form 4 February 2016

Accepted 11 February 2016

Available online 7 March 2016

\section{Keywords:}

Hair tress

Spreading

Penetration

Polymers

Cassie-Wenzel transition

\begin{abstract}
A B S T R A C T
The objective of the present work is to investigate wetting of hair tresses with the solutions of two polyacrylate polymers broadly used in cosmetic products. Wetting properties of the neutralized Aculyn-22 ${ }^{\mathrm{TM}}(\mathrm{A} 22)$ and Aculyn-33 ${ }^{\mathrm{TM}}$ (A33) polymer solutions on dry hair tresses are studied. Wetting behaviour on the dry undamaged hair tresses is drastically different between the two polymers and, in a first approximation, not directly linked with their bulk rheology. In the case of A22 the droplet spreads and remains on the tress after spreading for at least half an hour, during which it slowly evaporates and possibly penetrates inside the hair. For A33 fast penetration of the droplet inside the hair tress is observed when the advancing contact angle reaches a critical value of about $60^{\circ}$. It can be attributed to the so-called Cassie-Wenzel wetting transition, in which the liquid starts to penetrate inside the hair array.
\end{abstract}

(C) 2016 Elsevier B.V. This is an open access article under the CC BY-NC-ND license (http://creativecommons.org/licenses/by-nc-nd/4.0/).
Interactions between hair and water occur frequently not only in shower during application of the hair care products such as shampoos, conditioners or hair colourants, but also in contact with the atmospheric moisture. Water can absorb and diffuse into hair making it wet. As a result, the wetted strands stick to each other and form several clumps due to cohesive forces caused by water bridges [1]. Hair wettability, and how hair care products affect its wetting properties, is of considerable interest in cosmetic science [2,3].

The majority of research presented in the literature concentrate on interaction of a single hair fibre (dry or wet) with various liquids $[2,4-5]$; however, wetting of dry hair tresses with polymer solutions is largely unexplored up to now. This attracts significant interest from the industry, particularly for treatments which are applied on dry hair, e.g., for hair colouring products, hair styling products, leave-on conditioners and serums. There is a trend to minimize the use of harsh surfactant in such systems; cosmetic polymers with a pronounced affinity to interfaces, like Aculyn ${ }^{\mathrm{TM}} 22$ and Aculyn ${ }^{\mathrm{TM}} 33$ solutions, are such alternatives. These polymers are used in the production of shampoos, bath foams, foaming facial cleansers, hair styling gels, liquid soaps, lotions, moisturizing creams and hair colourants [6].

Below wetting of dry hair tresses by polymer solutions of Aculyn ${ }^{\mathrm{TM}} 22$ (A22) and Aculyn ${ }^{\mathrm{TM}} 33$ (A33) is investigated. A22 is a hydrophobicallymodified anionic alkali soluble polymeric emulsion, and A33 is an anionic alkali soluble, lightly crosslinked emulsion of the ethyl acrylate and methacrylic acid. General structures of the polymers are presented in

\footnotetext{
* Corresponding author at: Department of Chemical Engineering, Loughborough University, Loughborough LE113TU, UK.

E-mail address: V.M.Starov@lboro.ac.uk (V. Starov).
}

Refs. [7,8]. Aqueous solutions of the polymers in the concentration range $1.0-1.5 \% \mathrm{w} / \mathrm{w}$ were prepared by diluting and neutralizing the stock polymer emulsions with a $2 \%$ ammonia solution in ultra-pure water produced by Millipore $\mathrm{Q}$ and further buffered with ascorbic and citric acids $(0.2 \% \mathrm{w} / \mathrm{w}$ each). Sodium chloride $(\mathrm{NaCl})$ was added to the solutions in the range $0-1.5 \mathrm{M}$, and isopropyl alcohol (i-propanol, ipr-OH) was used at 0 or $1.67 \mathrm{M}(10 \% \mathrm{w} / \mathrm{w})$ concentration. Sodium dodecyl sulphate surfactant (SDS) was used at the concentration $5 \mathrm{mM}$. The above compositions have been chosen to represent typical systems used in the cosmetic applications where the polymers are utilized, for example in hair colourant applications. In our researches presented below and in Refs. $[9,10]$ the following procedures were used by Procter \& Gamble Co. to produce cosmetics formulations with A22 and A33. Rheology and surface tension measurements were conducted as described in Refs. $[9,10]$.

Blended human hair tresses (brown, Caucasian origin) were supplied by International Hair Importers, arranged into flat tresses of $12 \mathrm{~cm}$ length, width $2.5 \mathrm{~cm}$ and approximately $3 \mathrm{~mm}$ thickness. The average weight of the hair tress was $2 \mathrm{~g}$ and the average number of hair fibres in the tress was 4000 . For wetting measurements, the tresses were secured in a special custom made frame to provide as much hair alignment as possible. Frame allows fixing bunch of hair in a way which enables measurement of contact angle on hair. The surface of hair tress was as flat as possible. Example of hair arrangement is presented in Fig. 1.

The thickness of the tress was sufficient to avoid contact of the investigated liquid with the frame material. There was some expected variation in the arrangement of individual hair fibres on the frame in the course of repeated experiments, leading to a considerable standard 


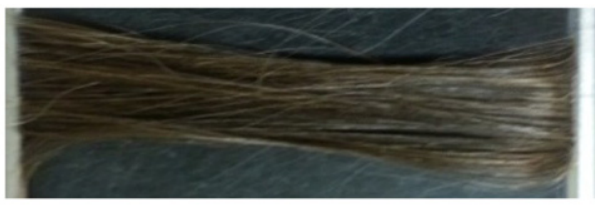

a)
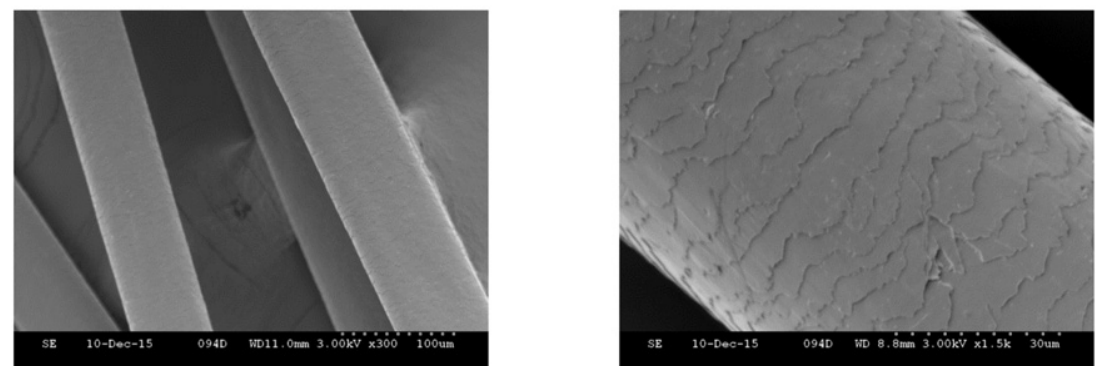

b)

Fig. 1. a) Example of hair tress used for contact angle measurements. b) SEM images of hair fibres.

error of measurements. The porosity of tress of hair was estimated as $\sim 0.43$ and the distance between the fibres was $\sim 17.4 \mu \mathrm{m}$.

Each hair tress was washed by a neutral shampoo, rinsed 3 times in distilled water and dried naturally. Measurements of the apparent contact angle were performed on dry hair tresses using the drop shape analysing software DSA 3, KRUSS. This software provides the contact angles $\theta$, the droplet volume $V$, and the droplet base diameter $D B$, all as a function of time $t$. The movies were recorded with a constant speed of $5 \mathrm{fps}$. The recorded process time below is defined as the time during which the droplet remains on the hair tress. During this time various parallel processes (spreading, penetration, and evaporation) occur. The initial contact angle was measured immediately after a droplet was placed on the support material. The final (advancing) contact angle is the contact angle after spreading stops, when the $D B$ reaches a constant value. All measurements were made at $20^{\circ} \mathrm{C}$ and $40 \%$ relative humidity. Teflonated silicon wafers (Teflon below) were selected as a reference support material for the contact angle measurements, as the initial contact angle on Teflon and hair tresses (both hydrophobic) is similar. It was demonstrated in Ref. [11] that there is no influence of the droplet volume on the contact angle measurement. In present experiments, the droplet volume was $2-3 \mu$ for each measurement. However, different droplet volumes resulted in different base diameters, but the differences were compensated in the equipment software by converting the base diameter into the equivalent volume.
In the case of measurements on Teflon, reproducibility was very good, and the relative standard error was around $2-3 \%$. When measuring on hair tresses, at least 10 repeated measurements were performed, however, the error was still in the range of $10-20 \%$ due to variations in the tress arrangement on the frame, as mentioned above.

Rheological and surface properties of the solutions under investigation are shown in Table 1. Data presented in Table 1 show that both polymers reduce surface tension, and the surface tension of the A33 solutions is lower than that of the A22 solutions. Both A22 and A33 solutions demonstrate well pronounced shear thinning behaviour. Viscosity is presented at shear rate $12 \mathrm{~s}^{-1}$ because this particular shear rate is of industrial interest. Viscosity decreases considerably with increase in the salt concentration, and remains always higher for the A22 solutions of comparable concentration vs. the A33 solutions. It was found that both bulk and surface viscoelasticity of the polymer mixtures depend rather smoothly on the content of A22, and no synergetic effects were observed. Therefore, it can be concluded that there is little interactions between the two polymers in solution within the studied concentration range.

Table 1 presents comparison of the wetting properties: the initial contact angle, the final contact angle (contact angle after spreading), the spreading time and the process time for the investigated solutions.

Initial contact angle of water on Teflon is around $110^{\circ}$, and on hair is around $100^{\circ}$. It confirms the expected hydrophobic nature of the

Table 1

Comparison of bulk viscosity, surface tension and wetting properties of investigated solutions on hair tresses.

\begin{tabular}{|c|c|c|c|c|c|c|}
\hline Solution & Surface tension ${ }^{1}, \mathrm{mN} / \mathrm{m}$ & Bulk viscosity at $12 \mathrm{~s}^{-1}, \mathrm{mPa} \mathrm{s}$ & Initial contact angle, deg & Spreading time, $\mathrm{s}$ & Final contact angle, deg & Process time, $\mathrm{s}$ \\
\hline Water & & 1 & 100 & $5-10$ & 90 & - \\
\hline A22 $1 \% 0.3 \mathrm{M} \mathrm{NaCl}$ & $42 \pm 1$ & $550 \pm 10$ & 100 & $10-20$ & 80 & 2000 \\
\hline A22 1\% $0.3 \mathrm{M} \mathrm{NaCl} 10 \%$ ipr-OH & $36 \pm 1$ & $400 \pm 7$ & 80 & $1-4$ & 60 & 2400 \\
\hline A22 1\% $0.3 \mathrm{M} \mathrm{NaCl} 5 \mathrm{mM}$ SDS & $35 \pm 1$ & $510 \pm 15$ & 90 & $40-50$ & 50 & 2000 \\
\hline A22 $1 \% 1.3 \mathrm{M} \mathrm{NaCl}$ & $38 \pm 1$ & $100 \pm 5$ & 100 & $10-20$ & 80 & 2000 \\
\hline A22 1\% $1.3 \mathrm{M} \mathrm{NaCl} 10 \%$ ipr-OH & $32 \pm 1$ & $40 \pm 5$ & 0 & \multicolumn{3}{|c|}{ Immediate penetration } \\
\hline A33 $1 \% 0 \mathrm{M} \mathrm{NaCl}$ & $30 \pm 1$ & $100 \pm 10$ & 100 & $5-25$ & 60 & 200 \\
\hline A33 $1 \% 0 \mathrm{M} \mathrm{NaCl} 10 \%$ ipr-OH & $33 \pm 1$ & $100 \pm 10$ & 90 & $1-5$ & 30 & 10 \\
\hline A33 1\% $0 \mathrm{M} \mathrm{NaCl} 5 \mathrm{mM}$ SDS & $32 \pm 1$ & $108 \pm 10$ & 90 & $1-5$ & 30 & 10 \\
\hline A33 1.5\% $0 \mathrm{M} \mathrm{NaCl}$ & $27 \pm 1$ & $500 \pm 50$ & 100 & $10-30$ & 60 & 100 \\
\hline A33 1.5\% $0 \mathrm{M} \mathrm{NaCl} 10 \%$ ipr-OH & $30 \pm 1$ & $500 \pm 50$ & 90 & $2-3$ & 50 & 60 \\
\hline A33 1.5\% $0 \mathrm{M} \mathrm{NaCl} 5$ mM SDS & $35 \pm 1$ & $560 \pm 10$ & 80 & $1-8$ & 25 & 70 \\
\hline $\mathrm{A} 22: \mathrm{A} 33=1: 1$ & - & $90 \pm 10$ & 100 & $25-80$ & 65 & 180 \\
\hline $\mathrm{A} 22: \mathrm{A} 33=1: 3$ & - & $40 \pm 10$ & 100 & $10-40$ & 50 & 140 \\
\hline $\mathrm{A} 22: \mathrm{A} 33=3: 1$ & - & $400 \pm 15$ & 100 & $40-50$ & 60 & 2000 \\
\hline
\end{tabular}

1 Ref. [10]. 

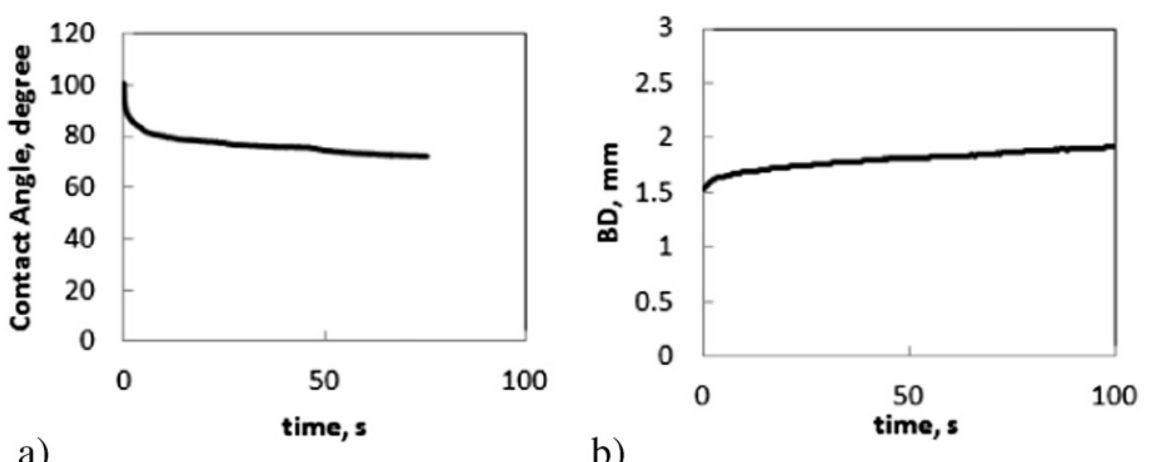

a)

b)

Fig. 2. A22 $1 \% 0.3 \mathrm{M} \mathrm{NaCl}$ solution on a hair tress. a) Contact angle and b) base line diameter.

undamaged hair fibre as its primary component is keratin. However, hair tresses are a porous support. Even more than that, it has two-type porous structure: (i) pores built by an array of individual fibres (slightly different in each measurement) and (ii) a fine porous structure of each individual hair fibre (see Fig. 2(b)) [12-14]. A hair tress demonstrates hydrophobic properties not only because of the hydrophobic nature of the hair surface, but also because of air pockets in between the fibres. That is, there are three possible wetting regimes: (a) Cassie wetting, where liquid is sitting on the hair tress, without penetration inside the tress, (b) Wenzel wetting, characterized by penetration of liquid into the hair tress, (c) transition from Cassie wetting to Wenzel wetting, after some critical contact angle is reached [15-18]. All three mentioned regimes were observed.

Dynamic contact angle and diameter of the base line of the A22 polymer solution droplets on the hair tress is presented in Fig. 2. In the case of Teflon, the initial contact angle of all A22 solutions ( $1 \%$ polymer, $0.3 \mathrm{M}$ and $1.3 \mathrm{M} \mathrm{NaCl}$ ) was $110^{\circ}$, and fast spreading over a short period of time around $20 \mathrm{~s}$ was observed. After the fast spreading stage the contact angle remained around $100^{\circ}$ and the droplet stayed on the support without changing its hemi-spherical shape. The initial contact angle on the hair tress for this polymer was about $100^{\circ}$. Spreading stopped after $10-20 \mathrm{~s}$, and the contact angle reached the value of $80^{\circ}$ (Fig. 2). The droplets remained on the surface of the hair tress after the initial fast spreading stage. Following this stage the total process time (until the droplet complete disappearance) was around 2000 s for both solutions (A22 1\% polymer, $0.3 \mathrm{M}$ and $1.3 \mathrm{M} \mathrm{NaCl}$ ). During this longer stage a slow evaporation and possible imbibition of the solutions into the hair were observed. Wetting properties of the solutions were very similar in spite of a considerable difference in their viscosities.

Wetting properties of the A33 solutions on Teflon are similar to that of the A22 solutions. Initial contact angle of both A33 solutions ( $1 \%$ and $1.5 \%$ polymer, $0 \mathrm{M} \mathrm{NaCl}$ ) on Teflon was about $100^{\circ}$ and duration of the fast spreading stage was around 40-50 s (slightly longer than A22).
The contact angle after spreading was around $80^{\circ}$ : the smaller contact angle in comparison with the A22 solutions is consistent with the lower surface tension of the A33 solutions (Table 1 ). The initial contact angle of the A33 solutions on the hair tress was about $100^{\circ}$. For the A33 $1 \% 0 \mathrm{M} \mathrm{NaCl}$ the first fast stage of spreading was completed after 5-25 s. For the $\mathrm{A} 331.5 \% 0 \mathrm{M} \mathrm{NaCl}$ this stage took $10-30 \mathrm{~s}$. In both cases the final contact angle after spreading was around $60^{\circ}$. The total process time, during which the droplet disappeared completely, was $100 \mathrm{~s}$ for A33 $1.5 \% 0 \mathrm{M} \mathrm{NaCl}$ and $200-250 \mathrm{~s}$ for $\mathrm{A} 331 \% 0 \mathrm{M} \mathrm{NaCl}$ (Table 1). It is important to notice that the droplet with higher viscosity disappeared faster.

Fig. 3 shows that in the case of A33 solutions, where the contact angle reached the critical value (around $60^{\circ}$ ), fast penetration into the hair tress was observed. This resulted in a "jump" on the graph of contact angle and diameter of the base line (Fig. 3). This can be explained by Cassie-Wenzel wetting transition: before reaching the critical contact angle (around $60^{\circ}$ ) the droplet was a Cassie state "sitting" on the outer surface of the hair tress; however, after the critical contact angle was reached then penetration of the liquid into the pores inside the porous media (like the hair tress in the case) by liquid started. Schematic penetration of the liquid inside the porous media (hair tress) is presented in Fig. 4. In the case of Cassie state, liquid wetted only the outer layer of the hair tress; however, at the Wenzel state liquid penetrated inside the hair tress. Capillary transport along fibres started after the transition. Such wetting transition is also observed on other keratin-built biological tissue, pigeon feathers, when it is irradiated by nitrogen and air plasma [19].

Figs. 2 and 3 proves that the conditions for wetting transition are to reach the critical contact angle, which is around $60^{\circ}$ in the case under consideration. This condition is satisfied for the A33 solutions and not satisfied for the A22 solution, the latter showing higher contact angle. The critical value of contact angle was obtained faster for the A33 1.5\% solution than that for the A33 1.0\% solution. It can be caused by slightly higher concentration of the trace surfactant carried over from the stock

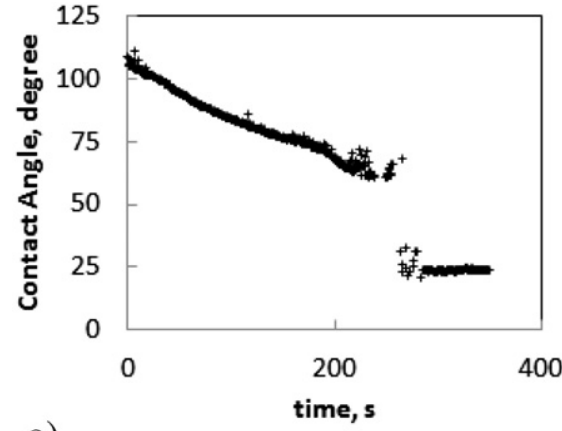

a)

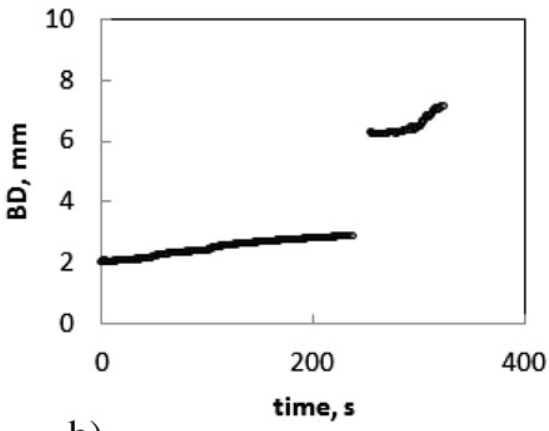

b)

Fig. 3. $\mathrm{A} 331 \% 0 \mathrm{M} \mathrm{NaCl}$ solution on a hair tress. a) Contact angle and b) base line diameter. 


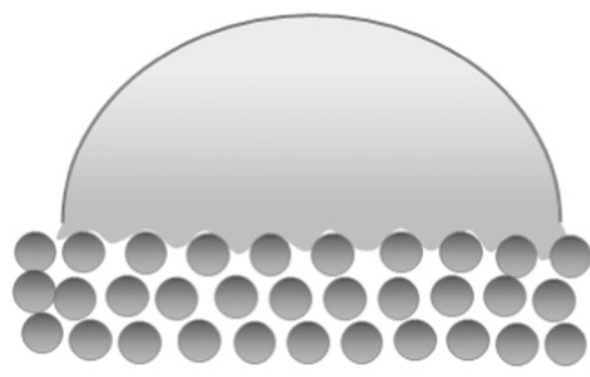

Cassie state

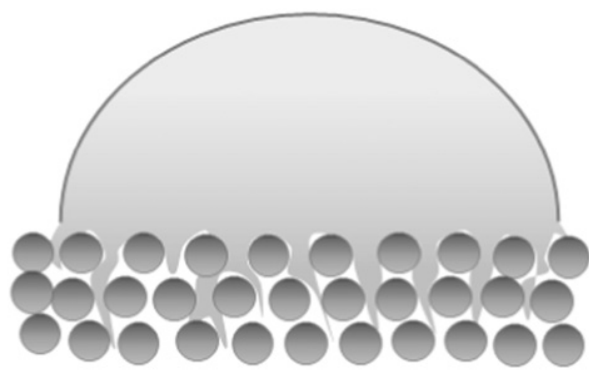

Wenzel state

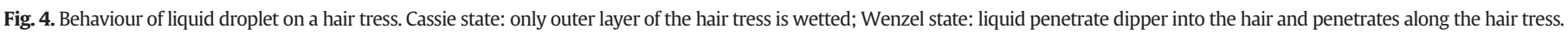

emulsion with the higher concentration of the polymer. The decrease of the total process time for the A33 solutions with added SDS confirms this observation. Differences in wetting behaviour of investigated solutions can be understood in terms of differences in polymer chemistry: A22 is a hydrophobically-associative polymer and has strong intermolecular associations and A33 is a microgel-type thickener that is not capable of strong intermolecular associations. It could be a reason why A33 solutions can reach critical contact angle on hair and penetrate into hair tress much faster than A22. However, other solution formulations can cause different molecule associations leading to a different wetting behaviour.

In most cases droplets of the A33 solutions behaved as described above, that is, underwent Cassie-Wenzel transition; however, there were few cases when the droplets only spread on hair tress but did not reach the critical contact angle $\left(60^{\circ}\right)$, and thus remained on the hair tress for a prolonged period of time. It could be caused by somewhat random arrangement of hair fibres on the surface of the tress (in spite of the forced alignment on the frame), and changed conditions favouring the Cassie-Wenzel wetting transition, which strongly depends on the roughness of the substrates and structure of the porous medium [16,17]. It confirms that in all experiments with hair tresses the hair arrangement plays a very important role.

The nature of the polymer determines wetting, spreading and imbibition behaviour on hair tresses. However, additives which modify the solution rheology and surface tension, including salts, solvents or surfactants, can influence the behaviour and wetting transition considerably. If certain viscosity or surface tension properties are targeted for a hair treatment, the polymer has to be carefully selected to ensure fast or slow penetration into the hair, depending on the purpose of an application.

\section{Acknowledgements}

This research was supported by Procter \& Gamble, USA and EU Marie Curie CoWet project (Grant No. 607861).

\section{References}

[1] W. Rungjiratananon, Y. Kanamori, T. Nishita, Comput. Graphics Forum 31 (2012) 1993-2002.

[2] R.A. Lodge, B. Bhushan, J. Appl, Policy. Sci. 102 (2006) 5255-5265.

[3] C. Zviak (Ed.), The Science of Hair Care; Informa Health Care, 1986

[4] R. Molina, F. Comelles, M.R. Julia, P. Erra, J. Colloid Interface Sci. 237 (2001) 40-46.

[5] Y.K. Kamath, C.J. Dansizer, H.D. Weigmann, J. Appl. Polym. Sci. 22 (8) (1978) 2295-2306.

[6] B.S. Lane, F. Vohra, S.K. Galazka, K.M. Nally, E.H. Agostino, G.S. Kerr, R.D. Lewis, M.T. Lund, S.D. McConaughy, Smith IIIE. D. 2012.

[7] http://www.dow.com/assets/attachments/business/pcare/aculyn/aculyn_22/tds/ aculyn22.pdf.

[8] http://www.dow.com/assets/attachments/business/pcare/aculyn/aculyn_33/tds/ aculyn33.pdf.

[9] A. Bureiko, A. Trybala, J. Huang, N. Kovalchuk, V.M. Starov, Colloids Surf. A 434 (2013) 268-275.

[10] A. Bureiko, A. Trybala, J. Huang, N. Kovalchuk, V.M. Starov, Colloids Surf. A. 460 (2014) 265-271.

[11] A. Trybala, A. Okoye, S. Semenov, H. Agogo, R.G. Rubio, F. Ortega, V.M. Starov, J. Colloid Interface Sci. 403 (2013) 49-57.

[12] O. Arjmandi-Tash, N. Kovalchuk, A. Trybala, V.M. Starov, Soft Matter 11 (2015) 3643-3652.

[13] A. Bureiko, O. Arjmandi-Tash, N. Kovalchuk, A. Trybala, V.M. Starov, Eur. Phys. J. Spec. Top. 224 (2015) 459-471.

[14] C. Robbins, Chemical and Physical Behaviour of Human Hair, third ed. SpringerVerlag, New York, 1994.

[15] J. Bico, U. Thiele, D. Quéré, Colloids Surf. A. 206 (1) (2002) 41-46.

[16] E. Bormashenko, et al., Langmuir 28 (7) (2012) 3460-3464

[17] L. Barbieri, E. Wagner, P. Hoffmann, Langmuir 23 (4) (2007) 1723-1734

[18] J. Wang, D. Chen, Langmuir 24 (18) (2008) 10174-10180.

[19] E. Bormashenko, R. Grynyov, Colloids Surf. B: Biointerfaces 92 (2012) 367-371. 